\title{
Salicylic Acid Produced by the Rhizobacterium Pseudomonas aeruginosa 7NSK2 Induces Resistance to Leaf Infection by Botrytis cinerea on Bean
}

\author{
Geert De Meyer and Monica Höfte
}

Lab of Phytopathology, Faculty of Agricultural and Applied Biological Sciences, Coupure Links, 653, B-9000 Gent, Belgium. Accepted for publication 21 February 1997.

\begin{abstract}
De Meyer, G., and Höfte, M. 1997. Salicylic acid produced by the rhizobacterium Pseudomonas aeruginosa 7NSK2 induces resistance to leaf infection by Botrytis cinerea on bean. Phytopathology 87:588-593.

Selected strains of nonpathogenic rhizobacteria can induce a systemic resistance in plants that is effective against various pathogens. In an assay with bean plants, we investigated which determinants of the rhizobacterium Pseudomonas aeruginosa 7NSK2 are important for induction of resistance to Botrytis cinerea. By varying the iron nutritional state of the bacterium at inoculation, it was demonstrated that induced resistance

lated metabolites in induced resistance by using mutants deficient in one or more siderophores. Results demonstrated that salicylic acid production was essential for induction of resistance to $B$. cinerea by $P$. aeruginosa 7NSK2 in bean and did not exclude a role for pyochelin. A role for pyoverdin, however, could not be demonstrated. Transcriptional activity of salicylic acid and pyochelin biosynthetic genes was detected during $P$. aeruginosa 7NSK2 colonization of bean. Moreover, the iron nutritional state at inoculation influenced the transcriptional activity of salicylic acid and pyochelin biosynthetic genes in the same way as it influenced induction of systemic resistance to $B$. cinerea.
\end{abstract} by $P$. aeruginosa $7 \mathrm{NSK} 2$ was iron-regulated. As $P$. aeruginosa $7 \mathrm{NSK} 2$ produces three siderophores under iron limitation, pyoverdin, pyochelin, and salicylic acid, we investigated the involvement of these iron-regu-
Additional keywords: induced systemic resistance, Phaseolus vulgaris, plant growth-promoting rhizobacteria, reporter gene.
Some nonpathogenic rhizobacteria can induce physiological changes throughout entire plants, making them more resistant to pathogens. This phenomenon, termed induced systemic resistance (ISR), has been demonstrated for various rhizobacteria in several plants $(2,19,24,36,40)$. The induced resistance reduces disease symptoms of a wide range of pathogens $(10,20-22,40)$, and its physiological characterization is in progress. In some cases, ISR by rhizobacteria is characterized by a systemic accumulation of pathogenesis-related proteins (24) that is also associated with pathogen-induced systemic acquired resistance (SAR) (39). In other cases, however, rhizobacterial ISR is not associated with an accumulation of pathogenesis-related proteins $(11,27)$.

How a rhizobacterium-root interaction leads to ISR is still unknown, but two kinds of bacterial determinants essential for ISR have already been described. The O-antigenic chain of outer membrane lipopolysaccharides (LPS) from Pseudomonas fluorescens WCS417r and WCS374 appears to be responsible for ISR to Fusarium wilt in radish (19). In addition, LPS from WCS417r were found essential for ISR to Fusarium wilt in carnation (37). However, LPS-deficient mutants of WCS374 and WCS417r were still able to induce resistance to Fusarium wilt in radish plants grown in a nutrient solution with low iron availability (18). At low iron availability, bacteria produce iron-chelating molecules, called siderophores, to acquire sufficient iron. Siderophores are excreted into the environment, and their iron complexes are selectively regained with specific membrane receptor proteins (17). Information about a role for siderophores in ISR is limited and controversial. A mutant of $P$. fluorescens $\mathrm{CHA}$, unable to produce the siderophore

Corresponding author: Monica Höfte; E-mail address: monica.hofte@rug.ac.be

Publication no. P-1997-0326-01R

(C) 1997 The American Phytopathological Society pyoverdin, lost the ability to induce ISR to tobacco necrosis virus in tobacco (24). In the low iron radish-Fusarium wilt system, pyoverdin-deficient mutants of $P$. fluorescens WCS374 and WCS417r induced the same resistance levels as the wild-type strains. In this system, however, a role for pyoverdin could not be excluded, because root application of pyoverdin purified from in vitro cultures of $P$. fluorescens WCS374 induced ISR (18). Salicylic acid (SA) is another siderophore produced by $P$. fluorescens WCS374, WCS417r (18), and CHA0 (24) that could be involved in ISR. SA is important in pathogen-induced SAR (4) and can induce a systemic resistance to pathogens after root or soil treatment $(7,18,24,35)$. Up to now, evidence for the involvement of bacterial SA in ISR is still circumstantial (18), because no SAdeficient mutants of ISR-inducing rhizobacteria have been tested on ISR induction.

$P$. aeruginosa $7 \mathrm{NSK} 2$ is a plant growth-promoting rhizobacterium (14) and an effective biocontrol agent of the root pathogen Pythium splendens in tomato (3). In iron-limiting conditions, this strain produces three siderophores: pyoverdin, pyochelin (12), and SA (3). The latter is also a precursor for pyochelin biosynthesis (32). In studies with siderophore-deficient mutants on tomato plants, pyoverdin or pyochelin proved necessary for wild-type biocontrol levels of Pythium damping-off (3). Pyoverdin and pyochelin most likely act by competition for iron with Pythium; however, for pyochelin, Buysens et al. (3) suggest a possible alternative mode of action through induced resistance. In the same study, a mutant that produced SA as the only siderophore retained some ability to suppress Pythium damping-off. The authors hypothesized that this was due to induced resistance by SA.

In this study, we demonstrate that $P$. aeruginosa 7NSK2 can induce systemic resistance to Botrytis cinerea by using a bean-based model system with $B$. cinerea as the challenging pathogen. In addition, we provide evidence that the bacterial siderophore SA is essential for induction of ISR by $P$. aeruginosa 7NSK2. 


\section{MATERIALS AND METHODS}

Bacterial strains, plasmids, plants, and culture conditions. Bacterial strains and plasmids used in this study are represented with their relevant characteristics in Table $1 . P$. aeruginosa and Escherichia coli strains were generally cultured at $37^{\circ} \mathrm{C}$ on LuriaBertani medium (LB) (30) amended with the appropriate antibiotics. For pseudomonads, antibiotics kanamycin, tetracycline, and carbenicillin were used at a concentration of $200 \mathrm{mg} \mathrm{liter}^{-1}$. For iron-limited growth, King's medium B (KB) (16) and casamino acids broth (38) were used. In $E$. coli cultures, the antibiotics tetracycline and carbenicillin were used at 20 and $50 \mathrm{mg} \mathrm{liter}^{-1}$, respectively. Selection against E. coli was performed using $10 \mathrm{mg}$ liter ${ }^{-1}$ of chloramphenicol.

All plant experiments were performed with bean (Phaseolus vulgaris) cultivar Prelude (Royal Sluis, Enkhuizen, the Netherlands). Unless otherwise mentioned, plants were grown in potting compost soil TRIOMF (TRIO BV, Westerhaar, the Netherlands) at $24 \pm 5^{\circ} \mathrm{C}$ in the greenhouse.

Construction of SA-deficient mutants of $P$. aeruginosa 7NSK2. SA-deficient mutants were made by gene replacement (32). The suicide plasmid pME3356, which contains a mutated $p c h$ A SA biosynthetic gene, was mobilized from $E$. coli S17-1 to $P$. aeruginosa $7 \mathrm{NSK} 2$ and to the pyoverdin-negative mutant MPFM1. With selection for tetracycline, pME3356 was integrated into the chromosome in a first crossing-over event. In a second crossing-over event, obtained after enrichment for tetracycline sensitive cells (28), plasmids were excised and lost because of their inability to replicate in $P$. aeruginosa. SA-negative mutants of strain MPFM1 were identified by their inability to form orange halos on casamino acids medium with chrome azurol S $(3,31)$. SA-negative mutants of strain 7NSK2 were identified by thin layer chromatography (TLC) of supernatant from iron-limited cultures (see below).

SA production in vitro. For both qualitative and quantitative analysis of SA production, strains were grown in casamino acids broth for $24 \mathrm{~h}$ at $200 \mathrm{rpm}$ and $34^{\circ} \mathrm{C}$ in the dark. Subsequently, 100 $\mu \mathrm{l}$ of this culture was transferred to $25 \mathrm{ml}$ of casamino acids broth and incubated for $36 \mathrm{~h}$ under the same conditions. Qualitative SA analysis of the culture supernatant (after centrifugation at 2,800 $\times$ $g$ for $15 \mathrm{~min}$ ) was performed with TLC after ethyl acetate extraction (3). To quantify SA production, the ethyl acetate extract was concentrated (1:3) under vacuum. SA concentration was determined by adding $5 \mu \mathrm{l}$ of $2 \mathrm{M} \mathrm{FeCl}_{3}$ and $3 \mathrm{ml}$ of water to $1 \mathrm{ml}$ of concentrated extract (25). The absorbance of the purple iron-SA complex, which developed in the aqueous phase, was measured at $527 \mathrm{~nm}$ and compared with a standard curve of SA dissolved in ethyl acetate.

Assay for induced resistance to $B$. cinerea. Bacterial inoculum for soil and bean treatment was prepared from LB or KB agar plates. Bacteria were scraped from the plates, washed twice in sterile demineralized water, and finally resuspended to a concentration of approximately $10^{9} \mathrm{CFU} \mathrm{ml}^{-1}$. Soil was mixed with bacterial inoculum to a concentration of $5 \times 10^{7} \mathrm{CFU} \mathrm{g}{ }^{-1}$, and bean seeds were soaked in the bacterial suspension for $5 \mathrm{~min}$ prior to planting. In control treatments, soil and bean seeds were treated with sterile demineralized water. To assay for induced resistance, B. cinerea isolate R16, resulting from the cross SAS56 $\times$ SAS405 (8), was grown to sporulation on tomato leaf agar (29). Spores were washed from 10-day-old cultures with sterile demineralized water containing $0.01 \%$ Tween 20 . After removing mycelial debris, the spore concentration was determined and adjusted to $10^{6}$ spores $\mathrm{ml}^{-1}$ to inoculate the first pair of leaves from 20-day-old bean plants. On both leaves, the epidermis was gently touched with a red hot pinhead at five spots. This resulted in 10 wounds of approximately $4 \mathrm{~mm}$ in diameter per plant that were each covered with $10 \mu \mathrm{l}$ of the $B$. cinerea inoculum immediately after wounding. After inoculation, plants were placed in a moist chamber, and the number of inoculations resulting in a grey, spreading $B$. cinerea lesion was counted 5 days later. At the end of every assay ( 25 days after planting), bacterial colonization of the roots was determined for three plants per treatment. Roots were washed to remove most of the soil, and $1 \mathrm{~g}$ of root was macerated in sterile demineralized water. Serial dilutions were plated on $\mathrm{KB}$, and bacterial counts were made after incubation at $37^{\circ} \mathrm{C}$.

Reporter gene expression on plant roots. To investigate in vivo transcriptional activity of pyochelin and SA biosynthetic genes on plant roots, the reporter plasmid pME3388 was mobilized from E. coli S17-1 to $P$. aeruginosa 7NSK2. Plasmid pME3388 carries the $p c h \mathrm{R} \ldots p c h \mathrm{D}$ promoter region of the $p c h \mathrm{DCBA}$ operon (33) fused to the reporter gene lacZ (C. Reimmann and D. Haas, personal communication). The pch DCBA operon is required for pyochelin and SA production in P. aeruginosa, and its transcription is highly iron-regulated (33). Reporter gene activity in $P$. aeruginosa 7NSK2 (pME3388) was checked in vitro in casamino acids broth amended with 0 to $20 \mu \mathrm{M} \mathrm{FeCl}_{3}$. $\beta$-galactosidase (EC 3.2.1.23) activity was determined with ONPG (onitrophenyl- $\beta$-D-galactopyranoside; Sigma Chemical Co., St. Louis) as substrate and expressed in Miller units (26). For in vivo gene expression experiments, beans were surface-disinfested with $0.1 \%$ $\mathrm{HgCl}_{2}$ for $7 \mathrm{~min}$, washed three times with sterile demineralized water, and germinated in autoclaved sand. Roots of 7-day-old seedlings were soaked in either $P$. aeruginosa 7NSK2 (pME3388) inoculum, prepared as above from LB or KB plates, or sterile demineralized water. Subsequently, seedlings were grown in glass tubes with autoclaved perlite and a half-strength Hoagland solution (9). Reporter gene expression was analyzed after root treatment and 7 and 14 days later. Briefly, roots were shaken vigorously in phosphate-buffered saline (30), and the $\beta$-galactosidase activity of the resulting solution was determined as above. Activities were

TABLE 1. Bacterial strains and plasmids used in this study

\begin{tabular}{|c|c|c|}
\hline Strain or plasmid & Relevant characteristics ${ }^{\mathrm{z}}$ & Reference or source \\
\hline \multicolumn{3}{|c|}{ Pseudomonas aeruginosa } \\
\hline 7NSK2 & $\mathrm{Pvd}^{+}, \mathrm{Pch}^{+}, \mathrm{SA}^{+}$, wild type & $3,14,15$ \\
\hline MPFM1 & $\mathrm{Pvd}^{-}, \mathrm{Pch}^{+}, \mathrm{SA}^{+}, \mathrm{Tn} 5$ mutant of $7 \mathrm{NSK} 2 ; \mathrm{Km}^{\mathrm{r}}$ & 14 \\
\hline 7NSK2-562 & $\mathrm{Pvd}^{+}, \mathrm{Pch}^{-}, \mathrm{SA}^{-}, p c h \mathrm{~A}$ replacement mutant of $7 \mathrm{NSK} 2$ & This work \\
\hline MPFM1-569 & $\mathrm{Pvd}^{-}, \mathrm{Pch}^{-}, \mathrm{SA}^{-}, p c h \mathrm{~A}$ replacement mutant of MPFM1; $\mathrm{Km}^{\mathrm{r}}$ & This work \\
\hline MPB1 & $\mathrm{Pvd}^{+}, \mathrm{Pch}^{+}, \mathrm{SA}^{+}, \beta$-galactosidase ${ }^{+}, \mathrm{Km}^{\mathrm{r}}$ & 13 \\
\hline \multicolumn{3}{|c|}{ 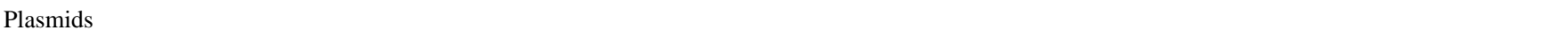 } \\
\hline pME3356 & pME3088 derived; contains the mutated $p c h \mathrm{~A}$ gene; suicide vector; $\mathrm{Tc}^{\mathrm{r}}$ & $32-2-2$ \\
\hline pME3388 & pKT derived; carries $p c h \mathrm{R} . . . p c h \mathrm{D}$ promoter region fused to $l a c \mathrm{Z} ; \mathrm{Cb}^{\mathrm{r}}$ & C. Reimmann and D. Haas \\
\hline
\end{tabular}

${ }^{\mathrm{z}}$ Abbreviations: $\mathrm{Pvd}=$ pyoverdin; $\mathrm{Pch}=$ pyochelin; $\mathrm{SA}=$ salicylic acid; and $\mathrm{Km}^{\mathrm{r}}, \mathrm{Tc}^{\mathrm{r}}, \mathrm{Cb}^{\mathrm{r}}, \mathrm{Tp}^{\mathrm{r}}$, and $\mathrm{Sm}^{\mathrm{r}}=$ resistant to kanamycin, tetracycline, carbenicillin, trimethoprin, and streptomycin, respectively. 
corrected for background with values from control plants. In parallel, the CFU count of the solution was determined, allowing $\beta$ galactosidase activity to be expressed in units per $10^{8}$ bacteria (6). Stability of plasmid pME3388 was verified by using LB with and without carbenicillin for bacterial counts.

Plant colonization by $P$. aeruginosa 7 NSK2 and mutants. To investigate bacterial colonization in detail, roots were treated with the strains $P$. aeruginosa MPB1, MPFM1, KMPCH, 7NSK2-562, and MPFM1-569 grown on KB as in the assay for induced resistance. Leaves, stems, and cotyledons of 20-day-old plants were checked for bacterial colonization. For four plants per treatment, leaves were macerated with $1.5 \mathrm{ml}$ of sterile demineralized water, and $100 \mu \mathrm{l}$ of the extract was plated on selective media. For MPFM1, KMPCH, MPFM1-569, and controls, LB with kanamycin was used; for MPB1, LB with kanamycin and $20 \mathrm{mg}$ of X-gal (5-bromo-4-chloro-3-indolyl- $\beta$-D-galactopyranoside; Sigma Chemical Co.) liter $^{-1}$ was used; and for 7NSK2-562, LB with $2.5 \mathrm{mM} \mathrm{Zn}$ was used. Cotyledons and stems of four plants per treatment were pooled before maceration in $1.5 \mathrm{ml}$ of sterile demineralized water and plated out on the same media. Bacterial counts were made after 24 and $48 \mathrm{~h}$ of incubation. The experiment was performed three times.

Experimental design and statistical analysis. All experiments with the assay for induced resistance consisted of seven or more replicates per treatment and were performed at least three times (see figures for details). The number of spreading $B$. cinerea lesions was analyzed by logistic regression analysis (1), because data were Poisson distributed. Treatments were considered to have fixed effects, and repeated experiments were considered as blocks in time. Data from experiments with common design were pooled for analysis when interaction between experiment and treatment was not significant at $P=0.05$ and variances were homogeneous.

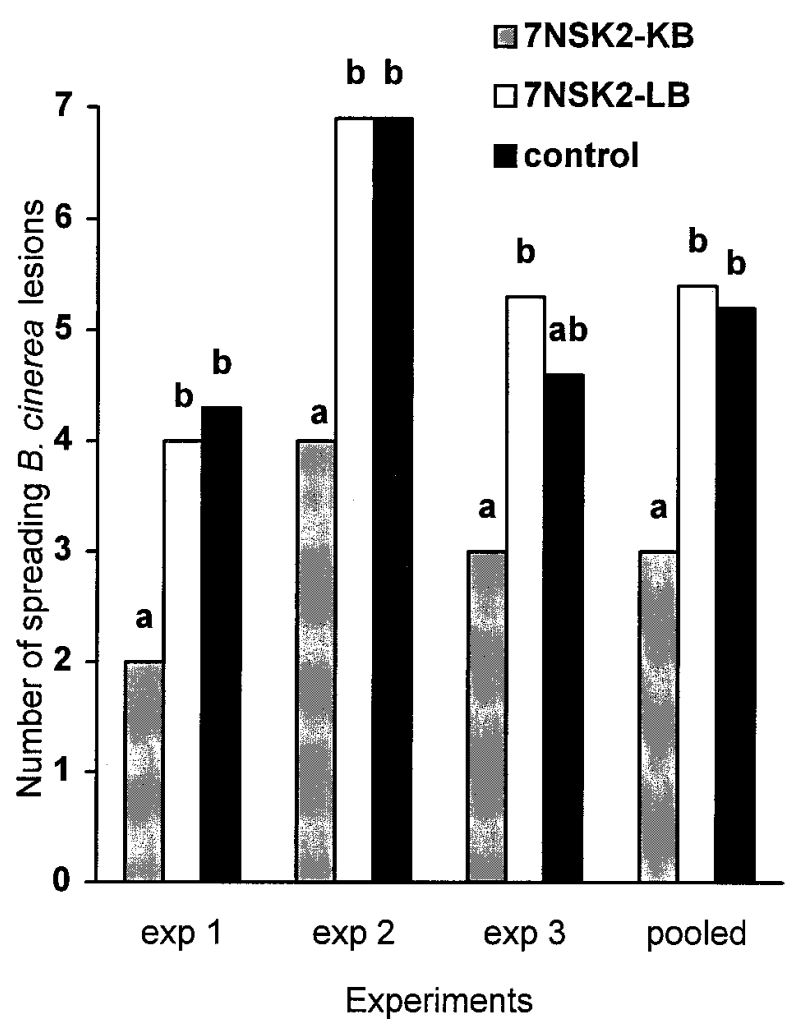

Fig. 1. Influence of root treatment with Pseudomonas aeruginosa $7 \mathrm{NSK} 2$ on the number of spreading Botrytis cinerea lesions on bean leaves. P. aeruginosa 7NSK2 was grown on King's medium B (KB) or Luria-Bertani medium (LB) prior to inoculation. Controls were treated with water. Data represent three repetitions of the same experimental setup. Every treatment consisted of eight replicates. Statistical analysis was performed by logistic regression analysis for every experiment and for pooled data from three experiments. Bars with a common letter do not differ significantly at $P=0.05$.
Root colonization was analyzed by analysis of variance on logarithmically transformed data after checking normality and homogeneity of variances. In vitro SA production was determined in triplicate per strain, and the experiment was performed three times. Data were analyzed by analysis of variance followed by Fisher's least significant difference procedure to compare means. Reporter gene expression on bean roots was determined for four replicates per treatment at every time point. Experimental data from both treatments were analyzed by Student's $t$ test for every time point. Statistical analysis was performed with SPSS (SPSS Inc., Chicago).

\section{RESULTS}

Iron nutrition and induced resistance to $B$. cinerea by $P$. aeruginosa 7NSK2. In preliminary experiments with $P$. aeruginosa 7NSK2 inoculum prepared from iron-rich LB, induced resistance to $B$. cinerea was only occasionally observed (data not shown). To investigate if this was due to the iron nutritional state at inoculation rather than to the resistance-inducing potential of this strain, inoculum from iron-rich LB was compared with inoculum from iron-limited $\mathrm{KB}$ on induction of resistance to $B$. cinerea. Treatment of bean roots with $P$. aeruginosa 7 NSK2 could significantly reduce the number of spreading $B$. cinerea lesions on the first leaves (Fig. 1). However, this was only observed when the bacterium was prepared from iron-limiting $\mathrm{KB}$ and not when grown on iron-rich LB. The effect of LB and KB on the iron nutritional state of $P$. aeruginosa 7NSK2 was visible by the color of the bacterial pellet: white for KB-grown and red for LB-grown bacteria. Induced resistance by $P$. aeruginosa $7 \mathrm{NSK} 2$ grown on $\mathrm{KB}$ was reproducible and seemed to be independent of the number of spreading $B$. cinerea lesions in the control treatment. In all three experiments, $P$. aeruginosa $7 \mathrm{NSK} 2$ prepared from KB reduced the number of spreading $B$. cinerea lesions by approximately two compared with the control plants, while the number of spreading $B$. cinerea lesions in control plants ranged from four to seven. Pooled over three experiments, root colonization was $\log _{10}$ $5.85 \pm 0.15$ and $\log _{10} 5.55 \pm 0.20 \mathrm{CFU} \mathrm{g}{ }^{-1}$ of fresh root for LB and $\mathrm{KB}$ treatment, respectively (values \pm standard error). Since the $F$ test in the analysis of variance was significant at $P=0.07$, both treatments were not significantly different.

Construction of SA-negative mutants of $P$. aeruginosa 7NSK2 and in vitro SA production. To study the involvement of SA in ISR by $P$. aeruginosa $7 \mathrm{NSK} 2$, two SA-negative mutants were generated that carried an insertion within the pchA gene: MPFM1-569 (pyoverdin', pyochelin ${ }^{-}, \mathrm{SA}^{-}$) and 7NSK2-562 (pyoverdin $^{+}$, pyochelin ${ }^{-}, \mathrm{SA}^{-}$). TLC analysis of culture supernatant extracts from MPFM1-569 and 7NSK2-562 showed that these mutants were unable to produce SA and pyochelin. Both mutants could be complemented for pyochelin production when the growth medium was supplemented with $10 \mathrm{mM} \mathrm{SA}$.

The in vitro SA production by $P$. aeruginosa 7NSK2 and derived strains was analyzed quantitatively by spectrophotometric detection of the purple iron-SA complex (Table 2). In this assay,

TABLE 2. In vitro salicylic acid (SA) production by Pseudomonas aeruginosa 7NSK2 and siderophore-negative derivatives at low iron availability, determined by spectrophotometric detection of the purple iron-SA complex $(527 \mathrm{~nm})$

\begin{tabular}{lc}
\hline P. aeruginosa strain & $\mathrm{SA}^{\mathrm{y}}\left(\mu \mathrm{g} \mathrm{ml}^{-1}\right)$ \\
\hline 7NSK2 & $5.6 \pm 1.7 \mathrm{a}$ \\
MPFM1 & $49.6 \pm 3.2 \mathrm{c}$ \\
KMPCH & $27.8 \pm 2.1 \mathrm{~b}$ \\
7NSK2-562 & $\mathrm{ND}^{\mathrm{z}}$ \\
7NSK2-569 & $\mathrm{ND}$ \\
\hline
\end{tabular}

y Means \pm standard error followed by the same letter are not significantly different at $P=0.05$ according to Fisher's least significant difference test.

${ }^{\mathrm{z}} \mathrm{ND}=$ values below the detection limit of $3 \mu \mathrm{g} \mathrm{SA} \mathrm{ml}{ }^{-1}$ culture supernatant. 
SA production by $P$. aeruginosa 7NSK2-562 and MPFM1-569 was not detected. This is a further confirmation that these strains are unable to produce SA. For 7NSK2, MPFM1, and KMPCH, significantly different SA production levels were obtained: MPFM1 and KMPCH produced nine and five times more SA, respectively, than the wild-type strain. Differences in SA production were not due to bacterial growth, since that was similar for all strains.

Siderophores involved in induced resistance to $B$. cinerea by $P$. aeruginosa 7NSK2. In experiments with bacterial inoculum prepared from $\mathrm{KB}$ plates, pyoverdin-negative strains $P$. aeruginosa MPFM1 and KMPCH (also pyochelin-negative) gave the same reduction in number of spreading $B$. cinerea lesions as the wild-type $P$. aeruginosa 7NSK2 (Fig. 2). SA-negative mutants 7NSK2-562 and MPFM1-569, on the other hand, lost the ability to induce resistance and gave numbers of spreading $B$. cinerea lesions similar to the control. Root colonization in these experiments was around $\log _{10} 5 \mathrm{CFU} \mathrm{g} \mathrm{g}^{-1}$ of fresh root and was not significantly different between bacterial treatments. In the analysis of variance, the $F$ test for bacterial treatment had a significance of $P=0.13$.

Iron nutrition and in vivo transcriptional activity of pyochelin and SA biosynthetic genes in $P$. aeruginosa 7NSK2. To obtain information about transcription of pyochelin and SA biosynthetic genes on bean roots, the reporter plasmid pME3388 was used. Reporter gene activity of $P$. aeruginosa 7NSK2 (pME3388) was clearly iron-regulated in vitro. $\beta$-galactosidase activity reached about 6,000 Miller units in iron-limiting casamino acids broth and was completely repressed in casamino acids broth amended with $20 \mu \mathrm{M} \mathrm{FeCl}{ }_{3}$. For two representative experiments, the $\beta$-galactosidase activity of $P$. aeruginosa 7NSK2 (pME3388) on bean roots is shown in Table 3. At the moment of inoculation, KBgrown $P$. aeruginosa 7NSK2 (pME3388) inoculum showed a clear

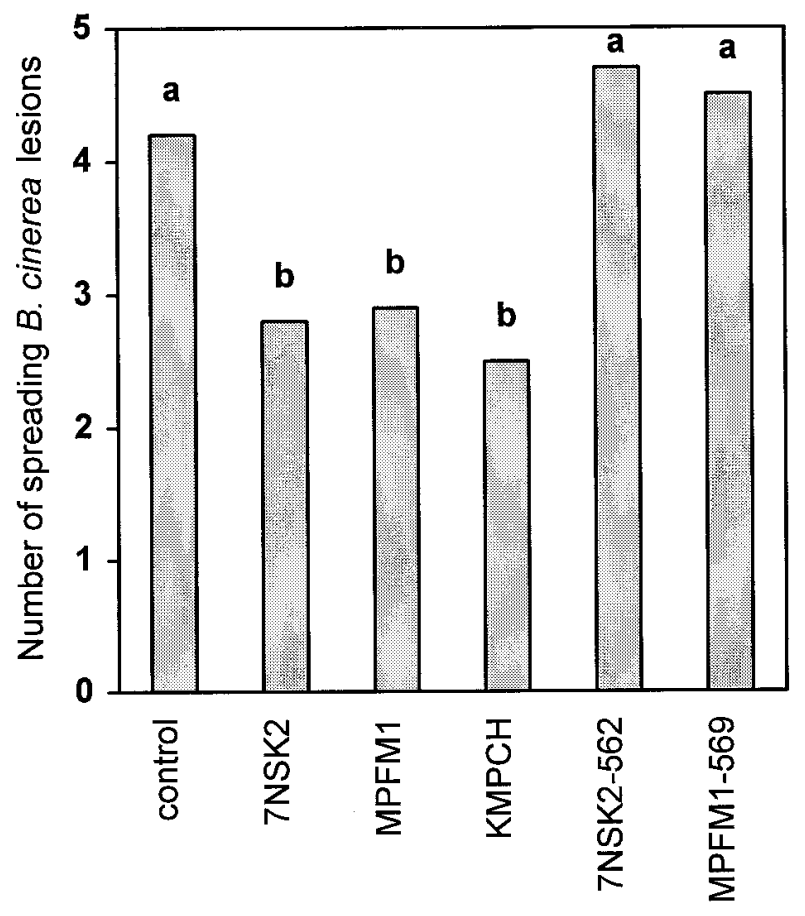

Bacterial treatment

Fig. 2. Influence of root treatment with Pseudomonas aeruginosa 7NSK2 and siderophore-deficient mutants on the number of spreading Botrytis cinerea lesions on bean leaves. All strains were grown on King's medium B prior to inoculation. Controls were treated with water. Every treatment consisted of seven replicates. Statistical analysis was performed by logistic regression on pooled data from six separate experiments. Bars with a common letter do not differ significantly at $P=0.05$. Strains used: 7NSK2 $\left(\mathrm{Pvd}^{+}, \mathrm{Pch}^{+}, \mathrm{SA}^{+}\right)$, MPFM1 (Pvd $\left.{ }^{+}, \mathrm{Pch}^{-}, \mathrm{SA}^{+}\right), \mathrm{KMPCH}\left(\mathrm{Pvd}^{-}, \mathrm{Pch}^{-}, \mathrm{SA}^{+}\right), 7 \mathrm{NSK} 2-562\left(\mathrm{Pvd}^{+}\right.$, $\left.\mathrm{Pch}^{-}, \mathrm{SA}^{-}\right)$, and MPFM1-569 $\left(\mathrm{Pvd}^{-}, \mathrm{Pch}^{-}, \mathrm{SA}^{-}\right)$. $\mathrm{Pvd}=$ pyoverdin, $\mathrm{Pch}=$ pyochelin, and $\mathrm{SA}=$ salicylic acid. reporter gene activity, while LB inoculum did not. Seven days after inoculation, some gene activity was detected on roots colonized by $P$. aeruginosa 7NSK2 derived from LB inoculum, but, in all experiments, this remained significantly lower than the activity on roots treated with KB-grown inoculum. After 14 days, the reporter gene activity in roots treated with LB inoculum increased and, in some experiments, it reached the same levels as the activity in roots treated with $\mathrm{KB}$ inoculum. In other experiments, however, the activity in LB inoculum remained significantly lower. In these studies, the background $\beta$-galactosidase activity was about 8 units $\mathrm{g}^{-1}$ of root and appeared to be fairly constant in all assays. The stability of plasmid pME3388 was about $90 \%$ under the experimental conditions used.

Plant colonization. To exclude direct antagonism between $P$. aeruginosa 7NSK2 and $B$. cinerea, possible systemic plant colonization by the bacterium was checked. $P$. aeruginosa 7NSK2 and derived mutants were never detected in stems and cotyledon extracts of root-treated bean plants. The detection limit of this assay is about $10 \mathrm{CFU}$ per stem or cotyledon. Occasionally, in $8 \%$ of the cases and randomly spread by bacterial treatment, inoculated $P$. aeruginosa strains were detected in extracts of first leaves. Bacterial counts, however, never exceeded $50 \mathrm{CFU}$ leaf $^{-1}$. Detection limit in this case is about 15 CFU leaf ${ }^{-1}$.

\section{DISCUSSION}

Beneficial effects of the rhizobacterium $P$. aeruginosa 7NSK2 on plants have been explained by plant-growth promotion (14) and biocontrol of soil pathogens (3). In this work, we investigated whether ISR is also involved. In a standardized assay with bean plants, root treatment with $P$. aeruginosa 7 NSK2 prepared from iron-limited $\mathrm{KB}$ consistently reduced the number of spreading $B$. cinerea lesions on the first leaves (Fig. 1). This was not due to direct effects from $P$. aeruginosa $7 \mathrm{NSK} 2$ on $B$. cinerea, because the bacterium and fungus were spatially separated. $P$. aeruginosa 7NSK2 was not recovered from cotyledons and stems and only occasionally recovered at very low concentrations from the first leaves. Therefore, the reduction in spreading $B$. cinerea lesions has to be attributed to ISR.

In contrast to $P$. aeruginosa $7 \mathrm{NSK} 2$ prepared from iron-limited $\mathrm{KB}$, the same inoculum prepared from iron-rich LB did not induce resistance to $B$. cinerea in bean (Fig. 1). As LB- and KB-grown $P$. aeruginosa 7NSK2 showed the same root colonization, the observed difference in ISR may be due to the different iron nutritional state of both inocula. At inoculation, LB-grown $P$. aeruginosa 7NSK2 had an internal iron pool that was visible in the red color of the bacterial pellet. An internal iron pool was not observed for KB-grown $P$. aeruginosa 7NSK2, because siderophoremediated iron acquisition is strictly regulated. These observations strongly suggest a role for iron-regulated metabolites of $P$. aeruginosa 7NSK2 in ISR. For ISR by $P$. fluorescens WCS374 and WCS417r in radish, a role for iron-regulated bacterial metabolites

TABLE 3. Reporter gene activity in Pseudomonas aeruginosa 7NSK2 (pME3388) on bean roots for inocula prepared from two different media ${ }^{\mathrm{x}}$

\begin{tabular}{lcccc}
\hline $\begin{array}{l}\text { Experiment } \\
\text { number }\end{array}$ & $\begin{array}{c}\text { Growth } \\
\text { medium }^{\mathrm{y}}\end{array}$ & 0 & \multicolumn{3}{c}{ Days after inoculation } \\
\cline { 3 - 5 } 1 & $\mathrm{LB}$ & ND $^{\mathrm{z}}$ & $8 \pm 1 \mathrm{a}$ & $113 \pm 12 \mathrm{a}$ \\
& $\mathrm{KB}$ & $358 \pm 40$ & $103 \pm 16 \mathrm{~b}$ & $233 \pm 19 \mathrm{~b}$ \\
& & & & \\
& LB & ND & $5 \pm 3 \mathrm{a}$ & $259 \pm 13 \mathrm{a}$ \\
& KB & $722 \pm 36$ & $147 \pm 10 \mathrm{~b}$ & $221 \pm 19 \mathrm{a}$ \\
\hline
\end{tabular}

$\times \beta$-galactosidase activities (units per $10^{8}$ bacteria) were measured with the reporter plasmid pME3388; means of four replicates per treatment \pm standard error. Per experiment and time point, values with the same letter do not differ significantly at $P=0.05$ by Student's $t$ test.

y LB = Luria-Bertani medium, KB = King's medium B.

${ }^{\mathrm{z}}$ Not different from background activity. 
was demonstrated with high and low iron plant nutrient solutions (18) or, in other words, by influencing the iron nutrition of the bacteria during root colonization. Apparently, the use of LB and $\mathrm{KB}$ inoculum served the same purpose in our setup, although the nutritional state of the inoculum might only affect the production of iron-regulated metabolites on roots during a limited period after inoculation.

Because $P$. aeruginosa 7NSK2-mediated ISR proved to be dependent on the iron nutritional state of the inoculum, the involvement of siderophores in ISR was investigated in detail by testing mutants deficient in the production of one or more siderophores. This is the first study in which SA-deficient mutants are included in this type of experiment. Because bacterial treatments were not different in root colonization, results in Figure 2 demonstrate unambiguously that SA production by $P$. aeruginosa 7NSK2 is necessary for ISR to $B$. cinerea in bean. All three strains able to produce SA, namely 7NSK2, MPFM1, and KMPCH, reduced the number of spreading $B$. cinerea lesions compared with control plants. On the other hand, two SA-deficient mutants, 7NSK2-562 and MPFM1-569, did not induce resistance to $B$. cinerea. Because SA-deficient mutants do not show a residual ISR compared with control plants, SA seems the only siderophore involved. However, a possible role for pyochelin cannot be excluded. Pyochelin is not exclusively essential for ISR because the pyochelin-deficient mutant KMPCH induces ISR, but it might play a role in ISR by 7NSK2 and MPFM1. This hypothesis, however, cannot be tested with siderophore-deficient mutants, because SA is a precursor for pyochelin biosynthesis (32). The conclusion that SA and maybe also pyochelin are responsible for ISR induction could explain the role of these siderophores in the biocontrol of the root pathogen Pythium splendens in tomato (3), but this statement needs confirmation in tomato. Experimental data (Fig. 2) show no role for pyoverdin in ISR to $B$. cinerea in bean by $P$. aeruginosa 7NSK2, because the number of spreading $B$. cinerea lesions in the 7NSK2562 treatment is equal to those in the control plants and 7NSK2562 makes pyoverdin as the only siderophore. This is similar to results with pyoverdin-deficient mutants of $P$. fluorescens WCS374 and WCS417r in the radish-Fusarium wilt assay (18). In tobacco, however, a pyoverdin-deficient mutant of $P$. fluorescens CHA0 lost the ability to induce ISR to tobacco necrosis virus (24). The role of pyoverdin in ISR induction remains, thus, controversial. Probably only a detailed study of several siderophore-deficient mutants from different strains in the same experimental setup will lead to a conclusive answer.

A role for SA produced by $P$. aeruginosa $7 \mathrm{NSK} 2$ in induced resistance to $B$. cinerea in bean is not surprising. SA is considered to mediate plant responses to pathogens (5) and is associated with pathogen-induced SAR (4). In most cases, SA application to plants has only a local effect on pathogens, but in tobacco, radish, and Arabidopsis, a systemic resistance to pathogens has been observed after root or soil treatment with SA $(7,18,27,35)$. In hydroponically grown radish plants, a range of SA concentrations from $100 \mu \mathrm{g}$ to $100 \mathrm{fg} \mathrm{root}^{-1}$ was able to induce ISR to Fusarium wilt, suggesting that there is no dose effect for SA (18). A dose effect for SA is also unlikely in our experiments. All three SA-producing strains, 7NSK2, MPFM1, and KMPCH, reduced the number of spreading $B$. cinerea lesions to the same extent (Fig. 2), although their in vitro SA production was quite different (Table 2). Compared with other rhizobacteria that induce systemic resistance, the in vitro SA production of $5.6 \mu \mathrm{g} \mathrm{ml}^{-1}$ by $7 \mathrm{NSK} 2$ is intermediate as P. fluorescens CHA0 (25), WCS417r, and WCS374 (18) produce 2,8 , and $55 \mu \mathrm{g} \mathrm{ml}^{-1}$, respectively. The higher levels of SA production in the pyoverdin-negative strains MPFM1 and KMPCH indicate that SA compensates for the lack of pyoverdin. This phenomenon was also observed for pyoverdin-deficient mutants of $P$. fluorescens $\mathrm{CHA0}$ (25).

In view of the essential role of SA and maybe pyochelin in ISR, the activity of SA and pyochelin biosynthetic genes (pchDCBA) was monitored on bean roots by using plasmid pME3388. Reporter gene activity on bean roots (Table 3 ) was clearly influenced by the iron nutritional state of the inoculum used (KB versus LB). Only 2 weeks after inoculation, equivalent levels of $\beta$-galactosidase activity were detected on bean roots treated with LB- and KB-grown $P$. aeruginosa 7NSK2 (Table 3). This indicates that from this moment on $\beta$-galactosidase activity reflects transcriptional activity of the SA and pyochelin biosynthetic genes in the rhizosphere, and no longer reflects the transcriptional activity expressed in the LB and KB inoculum. In a similar study with $P$. fluorescens Pf-5 grown in media with various concentrations of $\mathrm{FeCl}_{3}$ prior to inoculation, however, equivalent levels of transcriptional activity of a pyoverdin biosynthetic gene had already been reached $12 \mathrm{~h}$ after inoculation on bean roots (23). This difference could be explained by a higher iron availability in our setup that delays the need for siderophore production by the bacteria, but also the use of different reporter genes might be involved.

The high $\beta$-galactosidase activity measured during the first week after inoculation on roots treated with KB-grown $P$. aeruginosa 7NSK2 (Table 3) most likely reflects a residual transcriptional activity of SA and pyochelin biosynthetic genes expressed in the initial inoculum. This residual activity on roots treated with $\mathrm{KB}$ inoculum may result in SA and pyochelin production immediately after inoculation. By contrast, detectable $\beta$-galactosidase activities on roots treated with LB-grown $P$. aeruginosa 7NSK2 were only found at least 1 week after inoculation. This suggests that SA and pyochelin production on bean roots treated with LBgrown inoculum may only start at least 1 week after inoculation. In this respect, residual SA and pyochelin production on roots treated with $\mathrm{KB}$ inoculum might explain the observed induced resistance in our assay with $B$. cinerea, since ISR was only observed with $\mathrm{KB}$ inoculum but not with LB inoculum (Fig. 1). Our experiments with $P$. aeruginosa $7 \mathrm{NSK} 2$ reveal that the use of $\mathrm{KB}$ inoculum can only improve the induction of resistance and maybe this explains why, in many systems $(18,24,36), \mathrm{KB}$ inoculum is used for testing ISR by rhizobacteria.

In conclusion, SA appears to be essential for induction of resistance to $B$. cinerea in bean by the rhizobacterium $P$. aeruginosa 7 NSK2. How SA produced by $P$. aeruginosa 7NSK2 induces resistance remains to be elucidated. Systemic SA transport from roots to leaves is one possibility, but bacterial SA could also induce signals for systemic resistance at the root level.

\section{ACKNOWLEDGMENTS}

This work was supported by a grant from the Fund for Scientific Research-Flanders (FWO, Belgium) and by a specialization fellowship of the Flemish Institute for the stimulation of Scientific-Technological Research in Industry (IWT, Brussels, Belgium) that was given to G. De Meyer. M. Höfte was supported by a short-term fellowship under the OECD Project on Biological Resource Management. We thank C. Reimmann for providing the plasmid pME3388 and D. Haas for the opportunity to construct the salicylic acid mutants in his lab. We thank L. Delalande for her help during the course of this work.

\section{LITERATURE CITED}

1. Agresti, A. 1990. Categorical Data Analysis, John Wiley \& Sons, New York.

2. Alström, S. 1991. Induction of disease resistance in common bean susceptible to halo blight bacterial pathogen after seed bacterization with rhizosphere pseudomonads. J. Gen. Appl. Microbiol. 37:495-501.

3. Buysens, S., Heungens, K., Poppe, J., and Höfte, M. 1996. Involvement of pyochelin and pyoverdin in suppression of Pythium-induced dampingoff of tomato by Pseudomonas aeruginosa 7NSK2. Appl. Environ. Microbiol. 62:865-871.

4. Chasan, R. 1995. SA: Source or signal for SAR? Plant Cell 7:1519-1521.

5. Delanay, T. P., Uknes, S., Vernooij, B., Friedrich, L., Weymann, K., Negrotto, D., Gaffney, T., Gut-Rella, M., Kessmann, H., Ward, E., and Ryals, J. 1994. A central role of salicylic acid in plant disease resistance. Science 266:1247-1250. 
6. de Weger, L. A., Dekkers, L. C., van der Bij, A. J., and Lugtenberg, B. J. J. 1994. Use of phosphate-reporter bacteria to study phosphate limitation in the rhizosphere and in bulk soil. Mol. Plant-Microbe Interact. 7:32-38.

7. Enyedi, A. J., Yalpani, N., Silverman, P., and Raskin, I. 1992. Localization, conjugation, and function of salicylic acid in tobacco during the hypersensitive reaction to tobacco mosaic virus. Proc. Natl. Acad. Sci. U.S.A. 89:2480-2484.

8. Faretra, F., and Pollastro, S. 1991. Genetic bases of resistance to benzimidazole and dicarboximide fungicides in Botryotinia fuckeliana (Botrytis cinerea). Mycol. Res. 8:943-951.

9. Hoagland, D. R., and Arnon, D. I. 1938. The water culture method for growing plants without soil. Calif. Agric. Exp. Stn. Bull. 347.

10. Hoffland, E., Hakulinen, J., and van Pelt, J. A. 1996. Comparison of systemic resistance induced by avirulent and nonpathogenic Pseudomonas species. Phytopathology 86:757-762.

11. Hoffland, E., Pieterse, C. M. J., Bik, L., and van Pelt, J. A. 1995. Induced systemic resistance in radish is not associated with accumulation of pathogenesis-related proteins. Physiol. Mol. Plant Pathol. 46:309-320.

12. Höfte, M., Buysens, S., Koedam, N., and Cornelis, P. 1993. Zinc affects siderophore-mediated high affinity iron uptake systems in the rhizosphere Pseudomonas aeruginosa 7NSK2. Biometals 6:85-91.

13. Höfte, M., Mergeay, M., and Verstraete, W. 1990. Marking the rhizopseudomonas strain 7NSK2 with a Mu d(lac) element for ecological studies. Appl. Environ. Microbiol. 56:1046-1052.

14. Höfte, M., Seong, K. Y., Jurkevitch, E., and Verstraete, W. 1991. Pyoverdin production by the plant growth beneficial Pseudomonas strain 7NSK2: Ecological significance in soil. Plant Soil 130:249-258.

15. Iswandi, A., Bossier, P., Vandenabeele, J., and Verstraete, W. 1987. Effect of seed inoculation with the rhizopseudomonas strain 7NSK2 on the root microbiota of maize (Zea mays) and barley (Hordeum vulgare). Biol. Fertil. Soils 3:153-158.

16. King, E. O., Ward, M. K., and Raney, D. E. 1954. Two simple media for demonstration of pyocyanin and fluorescin. J. Lab. Clin. Med. 44:301-307.

17. Kloepper, J. W. 1993. Plant growth-promoting rhizobacteria as biological control agents. Pages 255-274 in: Soil Microbiol Technologies. B. Metting, ed. Marcel Dekker, Inc., New York.

18. Leeman, M., den Ouden, F. M., van Pelt, J. A., Dirkx, F. P. M., Steijl, H., Bakker, P. A. H. M., and Schippers, B. 1996. Iron availability affects induction of systemic resistance to Fusarium wilt of radish by Pseudomonas fluorescens. Phytopathology 86:149-155.

19. Leeman, M., van Pelt, J. A., den Ouden, F. M., Heinsbroek, M., Bakker, P. A. H. M., and Schippers, B. 1995. Induction of systemic resistance against Fusarium wilt of radish by lipopolysaccharides of Pseudomonas fluorescens. Phytopathology 85:1021-1027.

20. Liu, L., Kloepper, J. W., and Tuzun, S. 1992. Induction of systemic resistance against cucumber mosaic virus by seed inoculation with select rhizobacterial strains. (Abstr.) Phytopathology 82:1108-1109.

21. Liu, L., Kloepper, J. W., and Tuzun, S. 1993. Induction of systemic resistance against cucumber bacterial angular leaf spot caused by Pseudomonas syringae pv. lachrymans with two plant growth-promoting rhizobacterial strains. (Abstr.) Phytopathology 83:1340.

22. Liu, L., Kloepper, J. W., and Tuzun, S. 1995. Induction of systemic resistance in cucumber against Fusarium wilt by plant growth-promoting rhizobacteria. Phytopathology 85:695-698.

23. Loper, J. E., and Lindow, S. E. 1994. A biological sensor for iron available to bacteria in their habitats on plant surfaces. Appl. Environ. Micro- biol. 60:1934-1941.

24. Maurhofer, M., Hase, C., Meuwly, P., Métraux, J.-P., and Défago, G. 1994. Induction of systemic resistance of tobacco to tobacco necrosis virus by the root-colonizing Pseudomonas fluorescens strain CHA0: Influence of the gacA gene and of pyoverdine production. Phytopathology 84:139-146.

25. Meyer, J.-M., Azelvandre, P., and Georges, C. 1992. Iron metabolism in Pseudomonas: Salicylic acid, a siderophore of Pseudomonas fluorescens CHA0. Biofactors 4:23-27.

26. Miller, J. H. 1972. Experiments in Molecular Genetics. Cold Spring Harbor Laboratory, Cold Spring Harbor, NY.

27. Pieterse, C. M., van Wees, S. C. M., Hoffland, E., van Pelt, J. A., and van Loon, L. C. 1996. Systemic resistance in Arabidopsis induced by biocontrol bacteria is independent of salicylic acid accumulation and pathogenesis-related gene expression. Plant Cell 8:1225-1237.

28. Reimmann, C., Rella, M., and Haas, D. 1988. Integration of replicationdefective R68.45-like plasmids into the Pseudomonas aeruginosa chromosome. J. Gen. Microbiol. 134:1515-1523.

29. Salinas, J., and Schot, C. P. 1987. Morphological and physiological aspects of $B$. cinerea. Meded. Fac. Landbouwwet. Rijksuniv. Gent. 52:771-776.

30. Sambrook, J., Fritsch, E. F., and Maniatis, T. 1989. Molecular Cloning: A Laboratory Manual, 2nd ed. Cold Spring Harbor Laboratory, Cold Spring Harbor, NY.

31. Schwyn, B., and Neilands, J. B. 1987. Universal chemical assay for the detection and determination of siderophores. Anal. Biochem. 160:47-56.

32. Serino, L., Reimmann, C., Baur, H., Beyeler, M., Visca, P., and Haas, D. 1995. Structural genes for salicylate biosynthesis from chorismate in Pseudomonas aeruginosa. Mol. Gen. Genet. 249:217-228.

33. Serino, L., Reimmann, C., Visca, P., Beyeler, M., Della Ciesa, V., and Haas, D. 1997. Biosynthesis of pyochelin and dihydroaeruginoic acid requires the iron-regulated pchDCBA operon in Pseudomonas aeruginosa. J. Bacteriol. 179:248-257.

34. Simon, R., Priefer, U., and Pühler, A. 1983. A broad host range mobilization system for in vitro genetic engineering: Transposon mutagenesis in Gram negative bacteria. Biotechnology 1:784-790.

35. van Loon, L. C., and Antoniw, J. F. 1982. Comparison of the effects of salicylic acid and ethephon with virus-induced hypersensitivity and acquired resistance in tobacco. Neth. J. Plant Pathol. 88:237-256.

36. van Peer, R., Niemann, G. J., and Schippers, B. 1991. Induced resistance and phytoalexin accumulation in biological control of Fusarium wilt of carnation by Pseudomonas sp. strain WCS417r. Phytopathology 81:728734.

37. van Peer, R., and Schippers, B. 1992. Lipopolysaccharides of plantgrowth promoting Pseudomonas sp. strain WCS417r induce resistance in carnation to Fusarium wilt. Neth. J. Plant Pathol. 98:129-139.

38. Visca, P., Ciervo, A., Sanfilippo, V., and Orsi, N. 1993. Iron-regulated salicylate synthesis by Pseudomonas spp. J. Gen. Microbiol. 139:19952001.

39. Ward, E. R., Uknes, S. J., Williams, S. C., Dincher, S. S., Wiederholt, D. L., Alexander, D. C., Ahl-Goy, P., Métraux, J.-P., and Ryals, J. A. 1991. Coordinate gene activity in response to agents that induce systemic acquired resistance. Plant Cell 3:1085-1094.

40. Wei, G., Kloepper, J. W., and Tuzun, S. 1991. Induction of systemic resistance of cucumber to Colletotrichum orbiculare by select strains of plant growth-promoting rhizobacteria. Phytopathology 81:1508-1512. 